\title{
Peripheral laser iridoplasty opens angle in plateau iris by thinning the cross-sectional tissues
}

This article was published in the following Dove Press journal:

Clinical Ophthalmology

2I September 2013

Number of times this article has been viewed

Ji Liu ${ }^{1,2}$

Tania Lamba'

David A Belyea'

'Department of Ophthalmology, The George Washington University, Washington DC, USA; ${ }^{2}$ Yale Eye Center, Yale University, New Haven, CT, USA
Correspondence: David A Belyea Department of Ophthalmology, The George Washington University, 2150 Pennsylvania Ave NW, Suite 2A, Washington DC, 20037, USA

$\mathrm{Tel}+\mathrm{I} 20274 \mid 2800$

Email dbelyea@mfa.gwu.edu
Abstract: Plateau iris syndrome has been described as persistent angle narrowing or occlusion with intraocular pressure elevation after peripheral iridotomy due to the abnormal plateau iris configuration. Argon laser peripheral iridoplasty (ALPI) is an effective adjunct procedure to treat plateau iris syndrome. Classic theory suggests that the laser causes the contraction of the far peripheral iris stroma, "pulls" the iris away from the angle, and relieves the iris-angle apposition. We report a case of plateau iris syndrome that was successfully treated with ALPI. Spectral domain optical coherence tomography confirmed the angle was open at areas with laser treatment but remained appositionally closed at untreated areas. Further analysis suggested significant cross-sectional thinning of the iris at laser-treated areas in comparison with untreated areas. The findings indicate that APLI opens the angle, not only by contracting the iris stroma, but also by thinning the iris tissue at the crowded angle. This is consistent with the ALPI technique to aim at the iris as far peripheral as possible. This case also suggests that spectral domain optical coherence tomography is a useful adjunct imaging tool to gonioscopy in assessing the angle condition.

Keywords: plateau iris, optic coherence tomography, argon laser peripheral iridoplasty, angleclosure glaucoma

\section{Introduction}

Plateau iris syndrome is a unique subtype of angle closure glaucoma. It is commonly caused by anteriorly positioned ciliary processes that push the peripheral iris forward, resulting in angle closure. The diagnosis is always based on gonioscopic findings. ${ }^{1,2}$ Argon laser peripheral iridoplasty (ALPI) has been suggested to be useful in treating this condition by "stretching" the peripheral iris. ${ }^{3,4}$ High resolution anterior segment spectral domain optical coherence tomography (SD-OCT) is a very useful technology that can detect subtle structural changes in the iris and anterior chamber angles. ${ }^{5}$ The purpose of this study is to evaluate the mechanism of ALPI in treating plateau iris by anterior segment SD-OCT.

\section{Case report}

A 28-year-old Caucasian woman with a history of narrow angles in both eyes, who had bilateral laser peripheral iridotomies one year ago, presented with acute angle closure. Her presenting intraocular pressure was $26 \mathrm{mmHg}$ right eye and $31 \mathrm{mmHg}$ left eye. Gonioscopic exam revealed appositionally closed angles, with steeply elevated far peripheral iris configuration and double hump signs by indentation. Highfrequency ultrasound biomicroscopy confirmed the anterior location of the ciliary 
processes with incidental findings of one iris cyst in each eye. ALPI was performed in both eyes. Postlaser intraocular pressure was reduced to $10 \mathrm{mmHg}$ right eye and $12 \mathrm{mmHg}$ left eye. Anterior segment SD-OCT images were taken at 3,6,9, and 12 o'clock of the angle of each eye before and after laser iridoplasty. The anterior segment SD-OCT demonstrated closed angles, even with patent iridotomies. Gonioscopic exam after ALPI revealed angles were open to scleral spur in the areas of iridoplasty but remained appositionally closed in the untreated areas. The anterior segment SD-OCT taken one month after ALPI detected focal iris thinning in the areas which underwent laser treatment (Figure 1). Iris cross-sectional thickness was $278 \mu \mathrm{m}$ on average in the iridoplasty-treated areas compared with $315 \mu \mathrm{m}$ in the closed, untreated areas (Figure 2). (Student's $t$-test, $P<0.001)$.

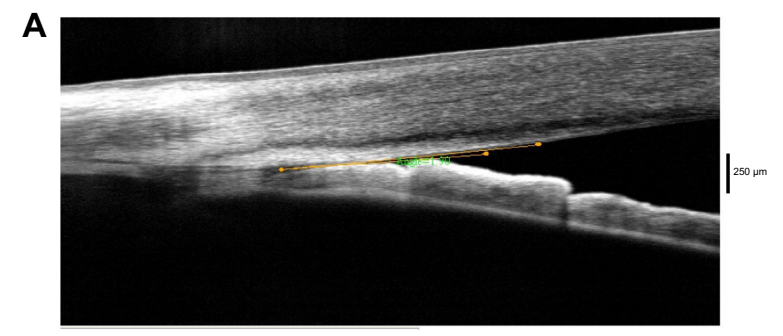

B

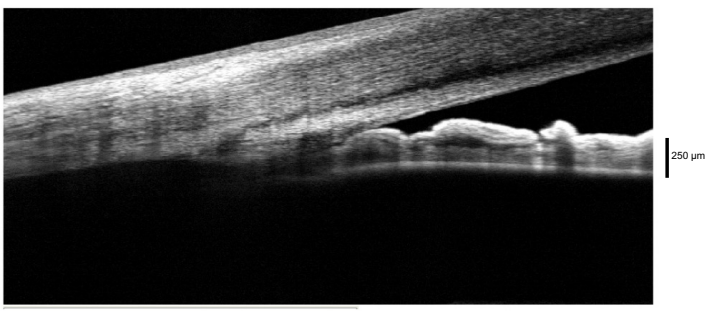

C

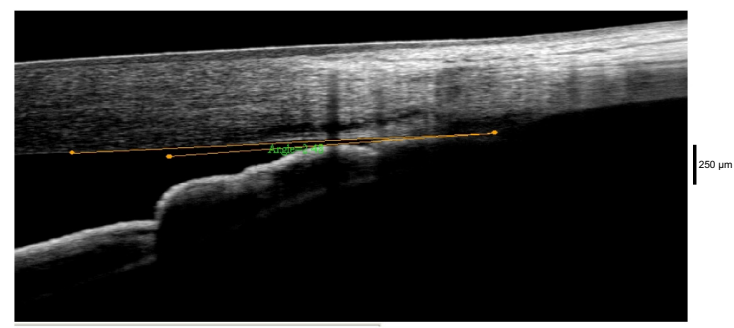

D

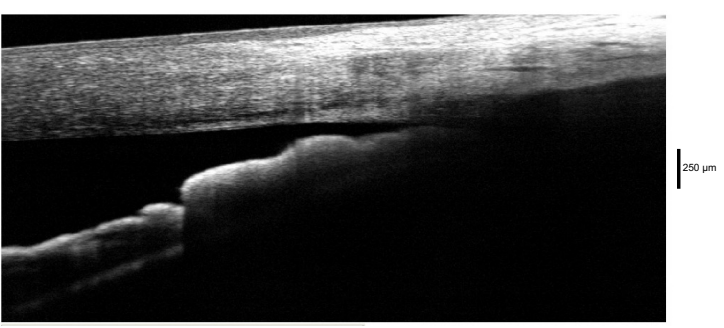

Figure I Angles open after laser iridoplasty at treated area.

Notes: The figures show the corresponding angle configurations prelaser ( $\mathbf{A}$ and $\mathbf{C}$ ) and postlaser (B and $\mathbf{D}$ ) treatment, assessed by spectral domain optical coherence tomography.

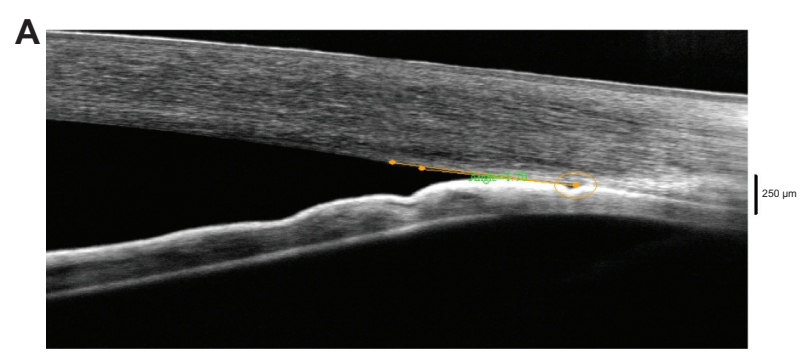

B

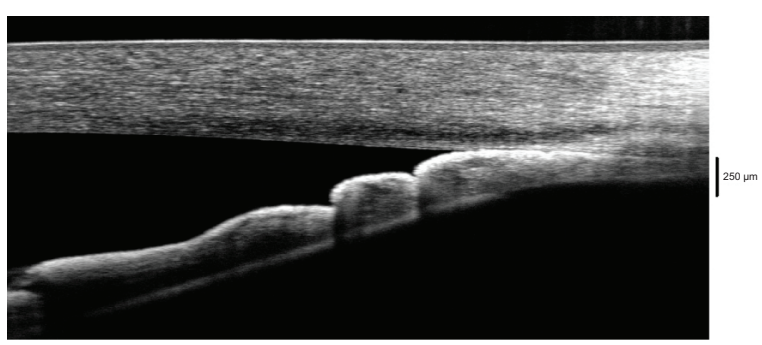

Figure 2 Angle remains closed after laser iridoplasty at untreated area. Notes: The figures show the corresponding angle configurations prelaser $(\mathbf{A})$ and postlaser (B) treatment, assessed by spectral domain optical coherence tomography.

\section{Discussion}

Anterior segment imaging is a useful adjunct tool to gonioscopy for the evaluation of angles. $.^{2,5-8} \mathrm{SD}-\mathrm{OCT}$ is a noncontact imaging test that is relatively easy to perform. It provides high resolution images of iris contour and angle configurations when properly performed. Compared to the widely used time-domain OCT, SD-OCT can better reveal details of angle structures such as Schlemn's canal. ${ }^{5}$ In our patient, SD-OCT clearly showed the change of angles before and after laser peripheral iridoplasty, which was consistent with gonioscopic findings. It can serve as a convenient adjunct tool in addition to the gonioscopy in the diagnosis and follow-up treatment for plateau iris syndrome. Because both mydriasis and miosis can affect iris shape, volume, cross-sectional thickness and alter the measurements, ${ }^{9-12}$ it is important to obtain images with the same pupillary dilation status. All our images, before and after ALPI, were taken under the same lighting conditions with pupils undilated. Though plateau iris with ALPI imaging was demonstrated previously with time-domain OCT, ${ }^{13,14}$ this is the first report that attempts to illustrate the mechanism of ALPI in treating plateau iris syndrome by using SD-OCT.

The traditional theory of ALPI in treating plateau iris is that the laser causes iris tissue shrinking, which stretches peripheral iris tissue away from the anterior chamber angle., The angle OCT in this patient clearly showed that the "thinning" effect on the peripheral iris tissue also plays an important role to open the angle. This finding can also explain why the ALPI always works best when the laser spots are placed as peripherally as possible. 


\section{Conclusion}

Plateau iris is a unique subtype of angle closure glaucoma. It is commonly caused by anteriorly positioned ciliary processes that push the peripheral iris forward, resulting in angle closure. Anterior segment SD-OCT demonstrates iris cross-sectional thinning as the mechanism responsible for opening the angle in plateau iris angle closure treated by laser iridoplasty.

\section{Disclosure}

The authors report no conflicts of interest in this work.

\section{References}

1. Cheng J, Buys YM, Spaeth GL. Confusion with the misuse of plateau iris terminology. J Glaucoma. 2013;22(3):265-266.

2. Kiuchi Y, Kanamoto T, Nakamura T. Double hump sign in indentation gonioscopy is correlated with presence of plateau iris configuration regardless of patent iridotomy. J Glaucoma. 2009;18(2):161-164.

3. Ritch R, Liebmann JM. Laser iridotomy and peripheral iridoplasty. In: Ritch R, Shields MB, Krupin T, editors. The Glaucomas. 2nd ed. St Louis, MO: Mosby; 1996:1549-1573.

4. Ritch R, Tham CC, Lam DS. Argon laser peripheral iridoplasty (ALPI): an update. Surv Ophthalmol. 2007;52(3):279-288.

5. Day AC, Garway-Heath DF, Broadway DC, et al. Spectral domain optical coherence tomography imaging of the aqueous outflow structures in normal participants of the EPIC-Norfolk Eye Study. Br J Ophthalmol. 2013;97(2):189-195.
6. Mandell MA, Pavlin CJ, Weisbrod DJ, Simpson ER. Anterior chamber depth in plateau iris syndrome and pupillary block as measured by ultrasound biomicroscopy. Am J Ophthalmol. 2003;136(5):900-903.

7. Liu L. Deconstructing the mechanisms of angle closure with anterior segment optical coherence tomography. Clin Experiment Ophthalmol. 2011;39(7):614-622.

8. Shabana N, Aquino MC, See J, et al. Quantitative evaluation of anterior chamber parameters using anterior segment optical coherence tomography in primary angle closure mechanisms. Clin Experiment Ophthalmol. 2012;40(8):792-801.

9. Quigley HA, Silver DM, Friedman DS, et al. Iris cross-sectional area decreases with pupil dilation and its dynamic behavior is a risk factor in angle closure. J Glaucoma. 2009;18(3):173-179.

10. Aptel F, Denis P. Optical coherence tomography quantitative analysis of iris volume changes after pharmacologic mydriasis. Ophthalmology. 2010;117(1):3-10.

11. Amini R, Whitcomb JE, Al-Qaisi MK, et al. The posterior location of the dilator muscle induces anterior iris bowing during dilation, even in the absence of pupillary block. Invest Ophthalmol Vis Sci. 2012;53(3): 1188-1194.

12. Jouzdani S, Amini R, Barocas VH. Contribution of different anatomical and physiologic factors to iris contour and anterior chamber angle changes during pupil dilation: theoretical analysis. Invest Ophthalmol Vis Sci. 2013;54(4):2977-2984.

13. Leung CK, Chan WM, Ko CY, et al. Visualization of anterior chamber angle dynamics using optical coherence tomography. Ophthalmology. 2005;112(6):980-984.

14. Kalev-Landoy M, Day AC, Cordeiro MF, Migdal C. Optical coherence tomography in anterior segment imaging. Acta Ophthalmol Scand. 2007;85(4):427-430.
Clinical Ophthalmology

\section{Publish your work in this journal}

Clinical Ophthalmology is an international, peer-reviewed journal covering all subspecialties within ophthalmology. Key topics include: Optometry; Visual science; Pharmacology and drug therapy in eye diseases; Basic Sciences; Primary and Secondary eye care; Patien Safety and Quality of Care Improvements. This journal is indexed on

Submit your manuscript here: http://www.dovepress.com/clinical-ophthalmology-journal

\section{Dovepress}

PubMed Central and CAS, and is the official journal of The Society of Clinical Ophthalmology (SCO). The manuscript management system is completely online and includes a very quick and fair peer-review system, which is all easy to use. Visit http://www.dovepress.com/ testimonials.php to read real quotes from published authors. 